\title{
A iniciação científica sob o ponto de vista de alunos de ensino médio como bolsistas do programa PIBIC-EM na área de neurofisiologia em uma instituição do interior do RS
}

\author{
The scientific initiation from the point of view of high school students as fellows of the High School
}

Program of Scientific Inititation in neurophysiology area in an institution of the interior of Rio Grande do

Sul state (Brazil)

Karine Ramires Lima' ${ }^{1}$ Mauren Souza ${ }^{1}$, Felipe P Carpes², Pâmela Billig Mello-Carpes ${ }^{1 *}$

${ }^{1}$ Physiology Research Group, Federal University of Pampa, Uruguaiana, Rio Grande do Sul, Brazil

${ }^{2}$ Applied Neuromechanics Group, Federal University of Pampa, Uruguaiana, Rio Grande do Sul, Brazil

*pamelacarpes@unipampa.edu.br

Support: CAPES; CNPq PIBIC-EM

\begin{abstract}
Scientific initiation (SI) consists in an opportunity, thought university, for students to expand their knowledge. In the Federal University of Pampa (Unipampa), the Institutional Program for Scientific Initiation Scholarships for High School Students (PIBIC/EM) was implemented in 2014 and there are still no indicators about the performance of the program and the high school students ("junior SI"). In this way, the aim of this work is to report, under the perspectives of five high school students that were junior SI thought CNPq PIBIC-EM in neurophysiology area, their expectations, experiences and the impacts of the junior SI in their lives. In order to evaluate the participation of high school students in the SI program a semi-structured interview was conducted after 1 year of involvement in the program. The students were very interested and participative during the period of involvement in the research groups and, in the light of their reports, we considered that this was a experience that positively impacted their lives.
\end{abstract}

Keywords: Scientific initiation; Junior scientific initiation; Research.

\section{Resumo}

A iniciação científica (IC) consiste na oportunidade, via universidade, dos estudantes expandirem seus conhecimentos. Na Universidade Federal do Pampa (Unipampa) o Programa Institucional de Bolsas de Iniciação Científica para alunos do Ensino Médio (PIBIC/EM) foi implementado em 2014 e ainda não há indicadores do desempenho do programa e dos bolsistas de IC do ensino médio ("IC júnior"). Desta forma, o objetivo deste trabalho é relatar, sob as perspectivas de cinco estudantes do ensino médio bolsistas CNPq PIBIC-EM atuantes na área de neurofisiologia, suas expectativas, experiências e os impactos da IC júnior em suas vidas. Para avaliar a participação dos alunos de IC júnior foi realizada, após o período de 1 ano de envolvimento no programa, uma entrevista semiestruturada. Os alunos demonstraram-se muito interessados e participativos durante o período de envolvimento no programa, e diante de seus relatos consideramos que esta foi uma experiência que impactou positivamente a vida dos alunos de IC júnior. 


\section{Ficha de atividade desenvolvida}

\begin{tabular}{|l|l|}
\hline Título & $\begin{array}{l}\text { A iniciação científica sob o ponto de vista de alunos de ensino médio como } \\
\text { bolsistas do programa PIBIC-EM na área de neurofisiologia em uma instituição } \\
\text { do interior do RS }\end{array}$ \\
\hline Público alvo & Alunos de ensino médio bolsistas PIBIC-EM \\
\hline $\begin{array}{l}\text { Disciplinas } \\
\text { relacionadas }\end{array}$ & $\begin{array}{l}\text { Fisiologia Humana, Bioquímica, Anatomia Humana, Fisiologia do Exercício, } \\
\text { Biomecânica, Biologia Geral, entre outras. }\end{array}$ \\
\hline $\begin{array}{l}\text { Objetivos } \\
\text { educacionais }\end{array}$ & $\begin{array}{l}\text { Despertar o interesse aos discentes pela pesquisa científica, envolvendo-os em } \\
\text { atividades de rotina em laboratório, bem como leitura e redação científica, ciclo } \\
\text { de debates e outras atividades relacionadas. }\end{array}$ \\
\hline $\begin{array}{l}\text { Justificativa } \\
\text { de uso }\end{array}$ & $\begin{array}{l}\text { Trata-se de uma estratégia de aproximação do discente de ensino médio à } \\
\text { universidade na tentativa de promover a disceminação e o incentivo à pesquisa } \\
\text { científica. }\end{array}$ \\
\hline $\begin{array}{l}\text { Conteúdos } \\
\text { trabalhados }\end{array}$ & $\begin{array}{l}\text { Protocolos das técnicas desenvolvidas, leitura e redação científica, pesquisas } \\
\text { científicas, entre outros. }\end{array}$ \\
\hline $\begin{array}{l}\text { Duração } \\
\text { estimada }\end{array}$ & \begin{tabular}{l} 
turnos semanais ao longo de 12 meses. \\
\hline
\end{tabular}
\end{tabular}




\section{Introdução}

A iniciação científica (IC) é uma experiência na qual o estudante desenvolve atividades relacionadas ao planejamento, execução, interpretação e comunicação de uma investigação científica e de seus resultados [1]. Ela consiste na oportunidade, via universidade, dos estudantes expandirem seus conhecimentos e desafia os jovens a pensar e fazer ciência, proporcionando-os maior contato com as características da carreira científica [2].

A IC deu-se início no Brasil no ano de 1951, quando a fundação do Conselho Nacional de Desenvolvimento Científico e Tecnologia (CNPq) passou a financiar esta atividade. O objetivo principal do programa de IC do CNPq é fomentar a ciência, tecnologia e inovação e atuar na formulação de suas políticas, contribuindo para o avanço das fronteiras do conhecimento, o desenvolvimento sustentável e a soberania nacional [3]. Em 1988 criou-se o Programa Institucional de Bolsas de Iniciação Científica (PIBIC), que visa apoiar a política de IC nas instituições de ensino e/ou pesquisa concedendo bolsas diretamente às instituições responsáveis pela seleção dos projetos dos orientadores pesquisadores interessados em participar do programa [4].

Na tentativa de promover uma política de incentivo à pesquisa, a IC, inicialmente restrita aos estudantes universitários, a partir de 2003, passou também a ser ofertada para estudantes da educação básica, mais precisamente para alunos do ensino médio, objetivando a disseminação das informações e conhecimentos científicos e tecnológicos básicos, e o desenvolvimento de atitudes, habilidades e valores necessários à educação científica e tecnológica dos estudantes [5].

A IC é uma importante oportunidade dada ao discente de inserir-se em uma nova realidade, podendo envolver-se em grupos de pesquisa e ser constantemente desafiado a novas aprendizagens, além de conviver com outros estudantes e professores, o que possibilita a socialização do conhecimento e produção científica [2].

Fava-de-Moraes e Fava (2000) [6] ressaltam a importância da IC como uma estratégia de contribuição para o desenvolvimento científico do país. Além disso, a política de ampliação da IC para o ensino fundamental e médio induz um processo de aproximação entre a graduação e a educação básica, que visa contribuir para o processo de domínio de habilidades como leitura e escrita e incentivar à inserção futura em cursos de graduação e programas de pós-graduação (PPGs) [2].

$\mathrm{Na}$ Universidade Federal do Pampa (Unipampa) o programa PIBIC/EM foi implementado em 2014, e ainda não há indicadores do desempenho do programa e dos 
bolsistas de IC do ensino médio (EM, também chamados de "IC júnior"). Atualmente (2017), a Unipampa possui 13 bolsistas PIBIC-EM, sendo 6 atuantes no campus Uruguaiana. Desta forma, o objetivo deste trabalho é relatar, sob as perspectivas de cinco estudantes do ensino médio, bolsistas CNPq PIBIC-EM na área de neurofisiologia, suas expectativas, experiências e os impactos da IC júnior em suas vidas, considerando a sua participação em grupos de pesquisa de fisiologia e neurociência da Unipampa, campus Uruguaiana.

\section{Metodologia}

Nos anos de 2014 a 2017 o Grupo de Pesquisa em Fisiologia (GPFis) e Grupo de Pesquisa em Neuromecânica Aplicada (GNAP) da Unipampa campus Uruguaiana/RS receberam em seus laboratórios alunos de IC júnior, estudantes do ensino médio de escolas públicas do município de Uruguaiana/RS. No total, os grupos de pesquisa entre os anos de 2014 a 2017 contaram com a participação de cinco alunos, com idade entre 14 e 17 anos, sendo que três alunos participaram das atividades realizadas no GPFis e os outros dois participaram das atividades propostas pelo GNAP.

\subsection{Seleção dos alunos de IC júnior}

Os alunos de IC júnior foram selecionados em períodos específicos, conforme o lançamento de editais. Para seleção, inicialmente foi realizada uma visita nas escolas por representantes da Unipampa em escolas da rede pública do município de Uruguaiana/RS cadastradas no programa institucional. Primeiramente foram divulgadas as atividades realizadas no campus Uruguaiana e as oportunidades de estudo que a universidade oferece. Posteriormente, convidamos os alunos interessados a se inscrever para concorrer às bolsas CNPq PIBIC-EM disponíveis.

Os alunos foram selecionados através de entrevistas com representantes dos respectivos grupos de pesquisa. Após essa entrevista, os estudantes com mais desenvoltura, capacidade de expressar suas ideias e com tempo disponível para a atuação na universidade foram comunicados sobre o fato de terem sido selecionados, para que comunicassem então aos seus pais ou responsáveis. Os pais ou responsáveis foram então comunicados, assinaram um termo genérico de concordância com a atuação do estudante na universidade, e no primeiro dia de atividade foram convidados a visitar a universidade junto com o estudante para o início das atividades. 


\subsection{Grupos de pesquisa}

Ambos os grupos desenvolvem suas pesquisas nas áreas de fisiologia e neurociência, realizando projetos de pesquisa, extensão e ensino.

O GPFis, criado em 2010, desenvolve projetos com humanos e modelos animais, tendo como principais linhas de pesquisa a neurofisiologia da memória e outros processos cognitivos e ensino de fisiologia.

O GNAP, criado em 2009, interessa-se em investigar a neuromecânica do movimento humano, bem como as interações entre mecanismos de controle do sistema nervoso central e geração de movimentos pelo sistema neuromuscular e suas interações com outras áreas, como a do comportamento animal, estresse e mecanismos bioquímicos.

\subsection{Estratégias de ação}

As estratégias de ação para implementar as atividades de laboratório no cotidiano dos alunos em sua IC júnior foram semelhantes em ambos os grupos, embora as atividades de pesquisa fossem diferentes. No quadro 1 são citadas as atividades gerais e mais importantes propostas aos alunos e destacadas as diferenças entre a participação em cada grupo de pesquisa, se necessário.

A carga horária estabelecida foi de, em média, 10 horas semanais, oferecendo aos alunos flexibilidade para a escolha dos dias conforme sua disponibilidade de horário, considerando também o horário escolar.

Desta forma, foi proposta aos alunos a participação em dois turnos por semana. Além da orientação pelo professor responsável pelo grupo de pesquisa, os alunos foram coorientados por pesquisadores de pós-doutorado e/ou alunos de pós-graduação e auxiliados pelos demais componentes do grupo. 
Quadro 1. Atividades propostas aos estudantes durante o período de IC júnior.

\begin{tabular}{|c|c|}
\hline Atividades Propostas & Descrição \\
\hline 1) Apresentação & $\begin{array}{l}\text { Apresentação do grupo de pesquisa e seus regimentos, assim como } \\
\text { protocolos das técnicas desenvolvidas, aos alunos selecionados. }\end{array}$ \\
\hline 2) Rotina de laboratório & $\begin{array}{l}\text { Atividades semanais para participação da rotina do laboratório, como } \\
\text { participação em grupos de estudo, tarefas de organização do laboratório, etc. }\end{array}$ \\
\hline $\begin{array}{l}\text { 3) Leitura e redação } \\
\text { científica }\end{array}$ & $\begin{array}{l}\text { Leitura de livros com conteúdos relacionados à área de pesquisa do grupo de } \\
\text { atuação, tais como "Fisiologia Humana: Uma abordagem integrada" de } \\
\text { Silverthorn, "Memória" de Iván Izquierdo, dentre outros, além de artigos } \\
\text { científicos; escrita sobre temáticas pré-selecionadas a partir do interesse dos } \\
\text { alunos, visando o desenvolvimento de habilidades de escrita científica. }\end{array}$ \\
\hline 4) Pesquisas científicas & $\begin{array}{l}\text { Participação dos alunos na prática em laboratório, inserindo-os em pesquisas } \\
\text { científicas, a fim de auxiliar os colegas nas atividades de seus projetos } \\
\text { específicos, sob supervisão de um aluno de pós-graduação, proporcionando } \\
\text { um entendimento das principais etapas da pesquisa científica. }\end{array}$ \\
\hline 5) Ciclo de debates & $\begin{array}{l}\text { Participação nos ciclos de debates semanais do grupo de pesquisa, que } \\
\text { visam oportunizar aos alunos de diferentes níveis a realização de } \\
\text { apresentações orais e debates de artigos científicos, propondo que cada } \\
\text { aluno seja responsável pela apresentação de ao menos um encontro } \\
\text { semanal por semestre. }\end{array}$ \\
\hline
\end{tabular}

\subsection{Avaliação}

Para avaliar a participação dos alunos de IC júnior, com intuito de identificar suas expectativas, experiências e os impactos da participação no programa em suas vidas foi realizada, após o período de participação de 1 ano no programa, uma entrevista semiestruturada com questões abertas. A entrevista contou com questões que abordaram quatro aspectos principais: i) conhecimentos prévios relacionados à pesquisa científica; ii) expectativas; iii) participação na IC júnior, e; iv) impactos: na vida pessoal, escolar e profissional. Apresenta-se no Quadro 2 as questões abordadas. 
Quadro 2. Questões utilizadas para avaliação da participação dos alunos de IC júnior

\begin{tabular}{|c|c|}
\hline Aspectos abordados & Questões \\
\hline \multirow{5}{*}{ Conhecimentos prévios } & 1. Já conhecia a Unipampa antes de iniciar o programa de IC? \\
\hline & 2. O que pensavas de uma universidade antes de ter esta experiência \\
\hline & como aluno de IC júnior? \\
\hline & 3. Tinhas conhecimento sobre IC e IC júnior? \\
\hline & 4. Tinhas conhecimento sobre fisiologia? \\
\hline \multirow{2}{*}{ Expectativas } & 5. Quais eram tuas expectativas em relação à IC? \\
\hline & 6. A IC foi o que imaginavas? \\
\hline \multirow{7}{*}{ Participação na IC júnior } & $\begin{array}{l}\text { 7. Achas que foi participativo em relação às atividades propostas? No } \\
\text { que achas que poderia melhorar? }\end{array}$ \\
\hline & 8. Qual a maior dificuldade que encontrastes durante a IC? \\
\hline & 9. O que mais gostou e o que menos gostou durante sua experiência? \\
\hline & $\begin{array}{l}\text { 10. Qual foi o maior aprendizado que tivestes ao participar deste } \\
\text { programa? }\end{array}$ \\
\hline & $\begin{array}{l}\text { 11. Achas que os horários das atividades propostas foram } \\
\text { suficientemente flexíveis? }\end{array}$ \\
\hline & $\begin{array}{l}\text { 12. Participastes ou participarias de atividades extras em outros } \\
\text { horários? }\end{array}$ \\
\hline & $\begin{array}{l}\text { 13. Vês a pesquisa científica relacionada com seu dia a dia? Em quais } \\
\text { aspectos? }\end{array}$ \\
\hline \multirow{6}{*}{$\begin{array}{l}\text { Impactos: na vida pessoal, } \\
\text { escolar e profissional }\end{array}$} & $\begin{array}{l}\text { 14. O que mudou em tua vida pessoal e profissional com esta } \\
\text { experiência? }\end{array}$ \\
\hline & $\begin{array}{l}\text { 15. A IC interferiu no teu desenvolvimento escolar? Se sim, em quais } \\
\text { aspectos? }\end{array}$ \\
\hline & 16. Tua experiência está repercutindo junto aos teus familiares, colegas, \\
\hline & $\begin{array}{l}\text { professores e demais pessoas de tua convivência? De que forma? } \\
\text { 17. Recomendarias a colegas e amigos que buscassem uma experiência }\end{array}$ \\
\hline & de IC? Por quê? \\
\hline & $\begin{array}{l}\text { 18. Pretendes seguir carreira científica? Se sim, em qual área? Se não, } \\
\text { que carreira/área pretendes seguir? }\end{array}$ \\
\hline
\end{tabular}

A entrevista foi realizada ao final do período de um ano de atuação nos grupos, individualmente, e foi gravada com o consentimento dos mesmos e posteriormente transcrita. As respostas serão relatadas e discutidas na sessão a seguir, seguindo a ordem dos aspectos abordados.

\section{Resultados e discussão}

Os alunos demonstraram-se bastante interessados e participativos durante 0 período de participação nos grupos de pesquisa, sendo que todos buscaram se envolver na maioria das atividades propostas. 


\section{I) Conhecimentos prévios}

A maioria dos alunos já conhecia a Unipampa antes de iniciar o programa de IC júnior, apesar de alguns nunca terem visitado o campus Uruguaiana anteriormente. Além disso, um dos alunos ressaltou desconhecer a gratuidade da universidade antes da sua atuação no programa PIBIC-EM. Quando perguntamos o que pensavam de uma universidade antes da participação do programa, um aluno ressalta:

\footnotetext{
"A população em geral não tem muito acesso ao campus, mas quando a gente vem e participa acaba tendo conhecimento dos projetos de pesquisa, que muitas vezes a sociedade não fica sabendo. Hoje em dia mudei muito o meu ponto de vista sobre pesquisas com animais, por exemplo." (Aluno de IC júnior 01).
}

Consideramos aqui a importância da aproximação da universidade com a sociedade. Santos Júnior (2013) [7] comenta que uma universidade enquanto uma instituição educativa tem papel social de fomentar ações educativas a fim de manter-se em constante diálogo com a sociedade. Diante disto, ações que aproximam a sociedade das instituições de ensino superior (IES) são de fundamental importância, pois permitem que a população tenha conhecimento do que a universidade oferece, aumentando suas possibilidades de ingresso na vida acadêmica. Ao inserir alunos do EM em atividades na universidade, devemos considerar que seus amigos, famílias e outras pessoas, além dos estudantes também acabarão indiretamente conhecendo um pouco da realidade da universidade.

Além disso, nenhum dos estudantes tinha conhecimento sobre a IC e também todos desconheciam o programa de IC júnior. Também não tinham conhecimento significativo sobre neurofisiologia, principal área de atuação dos grupos de pesquisa no qual participaram, alguns destacaram somente um conhecimento superficial de assuntos abordados em sala de aula.

A IC promove o desafio de relacionar o ensino com a pesquisa, e de ser um espaço para produção e não reprodução de conhecimento, nesta perspectiva, seu objetivo está em aproximar e fortalecer estas relações [8]. Embora o CNPq contribua para a divulgação da IC júnior no país, a iniciativa ainda fica restrita à participação de estudantes próximos de centros urbanos que possuem maior proximidade (geográfica, política) com IES ou Centros e Institutos de Pesquisa, desta forma uma parcela significativa de estudantes continua tendo pouco contato e conhecimento sobre o programa [9], o que também acaba 
sendo observado em cidades do interior nas quais a implantação de IES públicas ainda é um evento recente, como no caso da Unipampa.

\section{II) Expectativas}

Quanto às expectativas em relação à IC júnior, todos os alunos relataram que a busca pelo conhecimento e aprendizagem foram os principais fatores que fomentaram sua participação no programa. Também foi consenso entre eles que suas expectativas foram correspondidas durante seu período de participação nos grupos de pesquisa. Para reforçar, os alunos afirmaram que a IC foi "além do que imaginavam".

"Achava que ia somente ajudar nos projetos, mas após, eu vi que não era somente isso, meu orientador queria que eu melhorasse o que eu já sabia e que eu iniciasse um projeto meu. Por isso, minhas expectativas foram além do que eu imaginava" (Aluno de IC júnior 02).

Não é de hoje que são ressaltadas as influências da IC na vida de estudante. Bazin (1983) [10] compara o ensino médio, onde o estudante é dependente, com a universidade, onde a IC pode ser considerada como uma etapa a caminho da independência intelectual, onde se aproveita da curiosidade e interesse do estudante para que ele possa "fazer ciência", de modo que, ao desenvolver uma atividade ele aprende com ela, passando pelos processos de descobrir, entender e questionar sobre as verdades já impostas pela ciência.

\section{III) Participação na IC júnior}

Quanto à participação na IC júnior, todos concordaram ter sido participativos diante das atividades propostas, apesar de ressaltarem que poderiam melhorar em alguns aspectos, como na participação em outros projetos e nos debates semanais de artigos científicos. As maiores dificuldades encontradas durante a IC relatadas pelos alunos foram em relação à escrita e apresentações de trabalhos científicos.

As atividades práticas desenvolvidas foram o que os alunos mais gostaram durante sua experiência (Figura 1). Destacam-se entre os maiores aprendizados a possibilidade de aprender mais sobre o sistema nervoso, bem como a anatomia e fisiologia do cérebro, memória, além de aspectos relacionados ao emprego de tecnologias, como uso de sistemas de realidade virtual e de processamento de dados, além de apresentações de trabalhos científicos. 


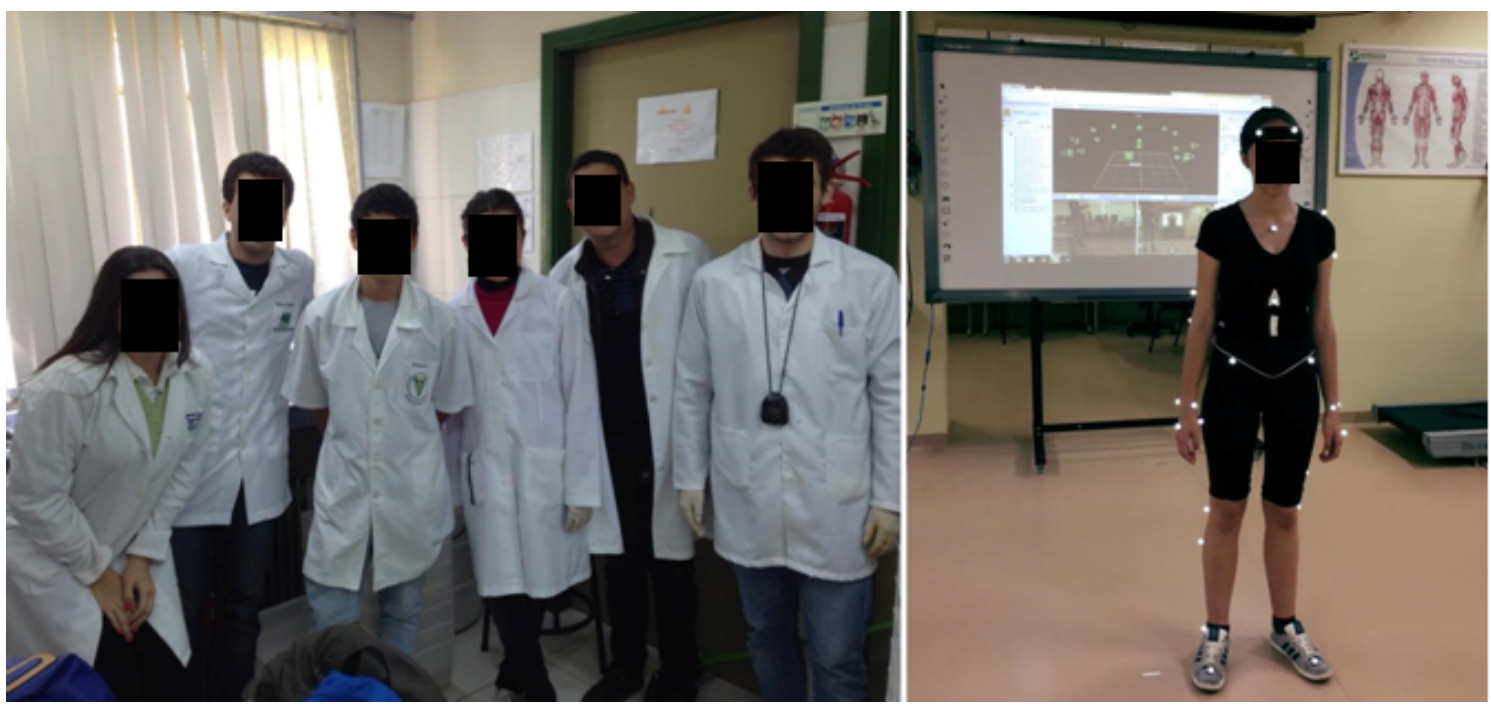

Figura 1. Alunos de IC júnior em atividades de pesquisa no laboratório. Imagem à esquerda, aluno de IC júnior (terceiro, da esquerda para direita) com seus colegas no Laboratório de Estresse, Memória e Comportamento do GPFis; imagem à direita, aluna de IC júnior participando de um experimento no Laboratório de Neuromecânica Aplicada, do GNAP. Fonte: material produzido pelos autores 2014/2016.

Os horários das atividades propostas foram considerados flexíveis por todos os estudantes. Além disso, a maioria dos alunos relatou ter participado de atividades extras em outros horários, como projetos de extensão, colóquios em fisiologia, curso de neurociência aplicada à educação, defesas de mestrado e doutorado, eventos científicos, dentre outros. Somado a isto, também houve a premiação de um trabalho desenvolvido por um dos alunos de IC júnior em um evento científico promovido anualmente pela Unipampa, o SIEPE - Salão Internacional de Ensino, Pesquisa e Extensão, que visa um espaço de trocas de saberes e experiências, e reúne exposições de projetos de ensino, pesquisa, extensão e trabalhos de iniciação científica com atrações musicais, cênicas, exposições de arte e painéis culturais.

Enfatizamos aqui o engajamento dos alunos na participação de atividades extralaboratoriais, como em eventos científicos, incluindo a apresentação de trabalhos nestes eventos. Para Aguiar (1997) [11], os estudantes tem prazer ao ver seu estudo divulgado e este seria um caminho de socialização profissional, uma vez que seu trabalho é reconhecido.

Quando questionados se viam a pesquisa científica relacionada com seu dia a dia, todos os estudantes concordaram que sim, relacionando as atividades desenvolvidas em laboratório com aplicações em seu cotidiano, ressaltando, por exemplo, atividades de caminhada, tema de um projeto desenvolvido pelo GNAP, e também projetos 
desenvolvidos pelo GPFis que abrangem a fisiologia do sistema nervoso, como sono, memória, patologias e seus possíveis tratamentos. Abaixo algumas citações dos alunos.

"(...) pude relacionar coisas do dia a dia, como por exemplo "por que eu sinto sono" com o funcionamento do cérebro" (Aluno de IC júnior 03).

"(...) há projetos que estudam a caminhada das pessoas, por exemplo, e que podem melhorar sua qualidade de vida" (Aluno de IC júnior 03).

"(...) todas as pesquisas buscam melhorias para as pessoas, pesquisas para a memória, como estudos sobre o chá verde associado para o tratamento de doenças, por exemplo" (Aluno de IC júnior 04).

A pesquisa permite maior aproximação com a realidade, permitindo melhor relacionamento entre a teoria e a prática [12]. Para Mendes (1991) [13], uma das perspectivas da pesquisa científica consiste exatamente em poder voltar-se para as reais necessidades da sociedade, visando o bem estar e a melhoria da qualidade de vida.

\section{IV) Impactos na vida pessoal, escolar e profissional}

Quanto às mudanças na vida pessoal e profissional dos estudantes, destaca-se, principalmente, o aumento do conhecimento. Os estudantes relataram sentirem-se mais interessados em pesquisar e aprender coisas novas. Todos ressaltaram que de alguma forma seu envolvimento no programa mudou positivamente sua maneira de pensar.

"Acho que quando a gente começa a ter contato com a carreira científica, começamos a ser mais críticos: investigar mais, procurar mais, não se restringir apenas ao "Google"... ir além, se questionar mais" (Aluno de IC júnior 04).

Outro aspecto relevante foi a contribuição da IC júnior para o desenvolvimento escolar, influenciando de maneira positiva, principalmente a matéria de ciências biológicas, cujo alguns conteúdos puderam ser mais aprofundados e vistos na prática sua aplicabilidade. Também foi amplamente citado que as atividades de escrita e seminários auxiliaram nas apresentações de trabalhos escolares (Figura 2).

"Consigo aplicar o conhecimento daqui para a escola e fazer as tarefas com menos dificuldade, o que também me ajudou nas apresentações de 

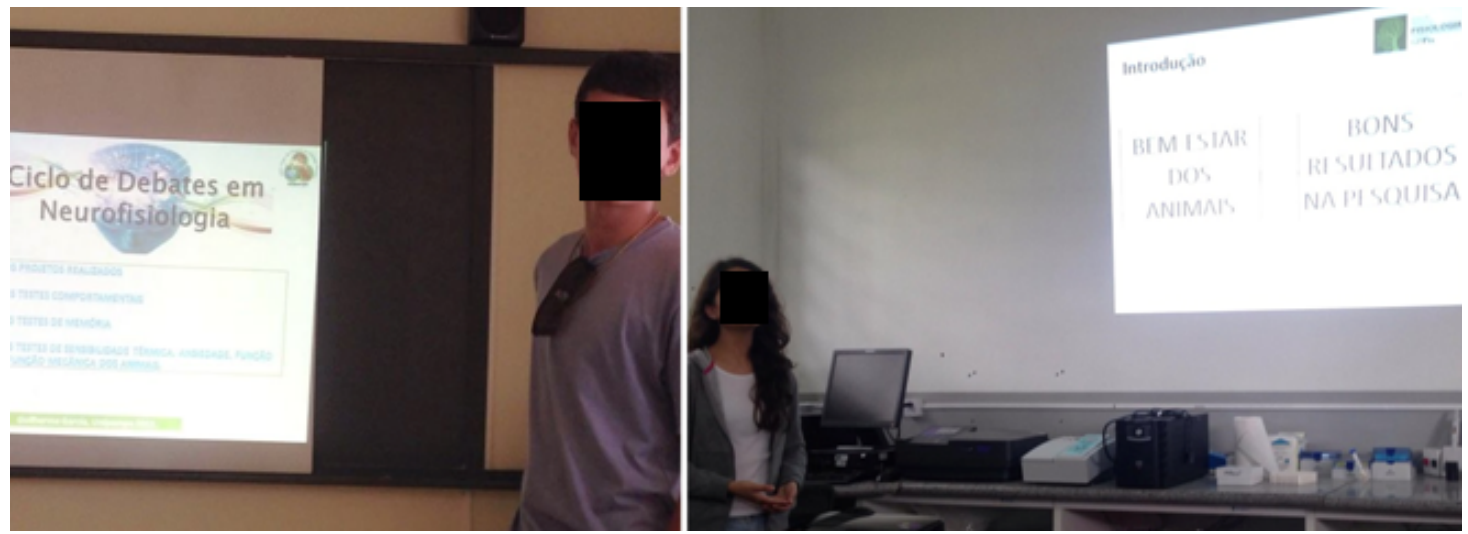

Figura 2. Alunos de IC júnior em apresentações de seminários nos Ciclo de Debates em Neurofisiologia, promovidos pelo GPFis. Fonte: material produzido pelos autores 2014/2016.

Os alunos mostraram-se muito empolgados com a repercussão de sua experiência junto a seus familiares, colegas, professores e demais pessoas de sua convivência, na figura 3 as alunas de IC júnior evidenciaram um dos elementos estudados no laboratório de neurofisiologia, o cérebro, através da disciplina de artes.

"Minha família ficou bastante interessada" (Aluno de IC júnior 05).

"Sempre que me perguntam sobre minha experiência e eu já procuro ensinar dizendo sobre os experimentos, os objetivos, já mostro os protocolos... meus colegas também demonstram interesse e alguns também sentem vontade em participar do programa" (Aluno de IC júnior 03).

"Acho que foi muito positivo, pois meu pai também começou a participar do laboratório, tanto meus pais como minha família me apoiaram e acharam muito positiva essa experiência, quanto à responsabilidade de ter uma carga horária e também poder levar essa experiência para escola. Muitos colegas me perguntavam se também teriam a oportunidade de participar do programa " (Aluno de IC júnior 01).

De modo geral, é consenso que a IC desempenha um papel relevante na formação dos estudantes, tanto em relação ao seu desenvolvimento pessoal, quanto à construção da uma nova visão de ciência e à socialização profissional [8]. Podemos citar inúmeras vantagens que a IC pode trazer ao estudante, a primeira delas é a fuga da rotina e da estrutura curricular à qual o aluno está acostumado, além de ajudar a desenvolver habilidades na fala e escrita, o estudante torna-se mais crítico e com maior discernimento 
para enfrentar as dificuldades [6].

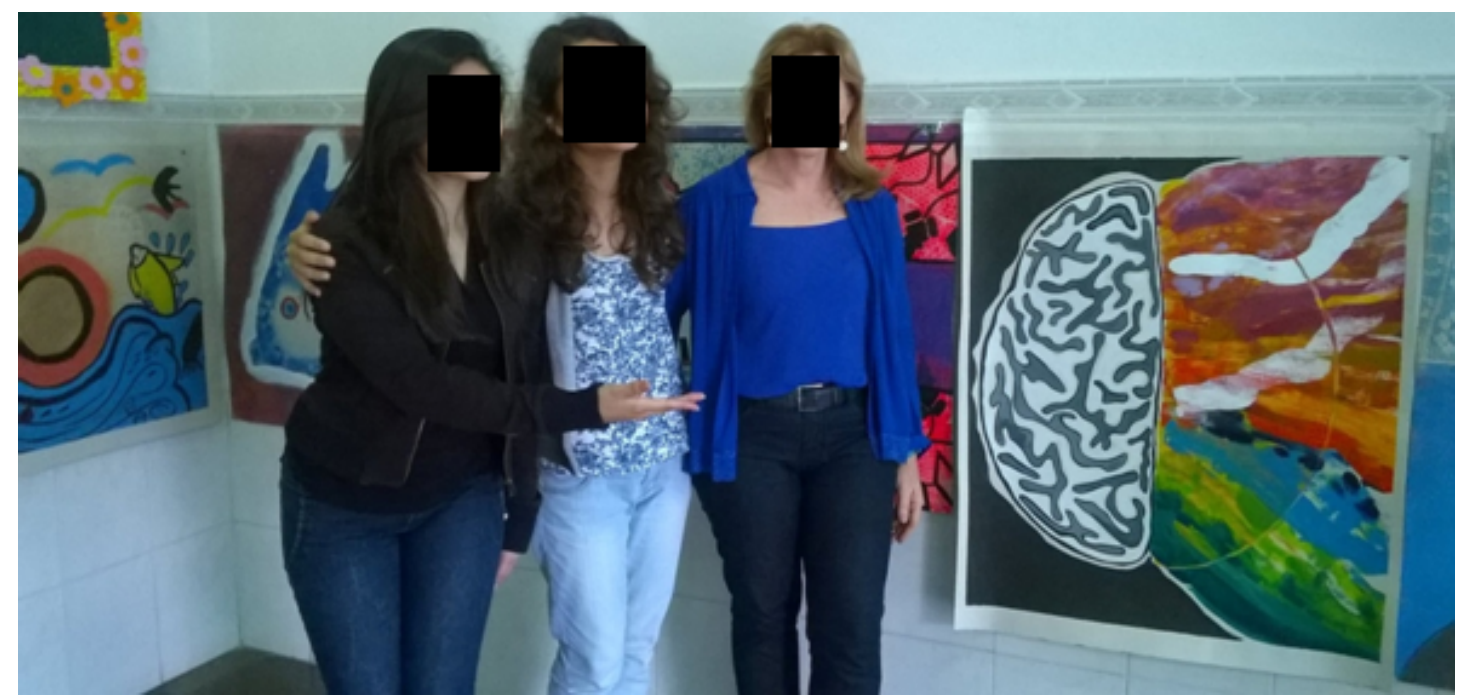

Figura 3. Alunas de IC júnior e professora de artes em uma exposição de trabalhos em sua escola. Fonte: material produzido pelos autores 2014/2016.

Para finalizar perguntamos aos estudantes se recomendariam a colegas e amigos a experiência de IC e todos concordaram, destacando o programa como uma forma de agregar ao conhecimento e uma oportunidade de aprender além do que a escola oferece, incentivando bons hábitos, como cumprimento de horários e responsabilidade com os trabalhos e atividades realizadas. Em relação ao futuro, os estudantes mencionaram não saber se pretendem seguir a carreira científica, apesar de terem gostado da experiência, mas todos demonstraram interesse em continuar sua formação ingressando no ensino superior.

Apesar da IC contribuir para a perspectiva do aluno em dar continuidade a sua formação acadêmica [14], muitos autores destacam a importância da IC para a atuação profissional fora do ambiente de pesquisa.

Para Fava-de-Moraes e Fava (2000) [6] é um erro admitir que IC existe exclusivamente para formar cientistas, o estudante poderá usufruir de seus aprendizados tanto dentro como fora do âmbito acadêmico, através de uma melhor capacidade de análise crítica, maturidade intelectual e capacidade para resolver problemas. Breglia (2002) [15] ressalta: "a vivência da pesquisa é um diferencial para o que chamam de 'mercado de trabalho". 
V) Os desafios do programa de IC júnior

Pode-se dizer que implementar este programa em ambos os laboratórios citados foi desafiador, tendo em vista que há poucos relatos na literatura de atividades que envolvam alunos de IC júnior em laboratórios de pesquisa científica. Portanto, foi preciso pensar em uma proposta de atividades que envolvesse os alunos na pesquisa, mas que também maximizasse seus conhecimentos tanto na área de atuação dos grupos como em atividades que poderiam auxiliar no seu desenvolvimento escolar e futuro profissional.

Neste sentido propomos atividades simples, deixando os alunos livres para aprofundar-se nas temáticas e atividades que lhe despertaram maior interesse e procuramos fornecer ferramentas como livros e computadores para consultas de periódicos e artigos científicos para que os mesmos desenvolvessem habilidades de busca pelo conhecimento, além de estimular seu senso crítico, tomada de decisão e habilidades para escrita e fala ao público.

É preciso considerar que, embora os alunos possam não seguir a carreira científica futuramente, este programa lhes permitiu ampliar seus horizontes, apresentando-os uma nova visão sobre a ciência e incentivando-os ao estudo e à busca pelo conhecimento.

Destacamos que, embora tenhamos entrevistado apenas 5 estudantes de EM atuantes como bolsistas PIBIC-EM em uma área específica, principalmente pelo fato da UNIPAMPA ter entrado no programa recentemente e termos tido, até então, poucos bolsistas, acreditamos que o impacto de atividades de IC no EM tende a ser semelhante em diferentes áreas. Além disso, é importante divulgar a importância de programas como este, a fim de encorajar o envolvimento de mais cientistas orientando alunos da Educação Básica, assim como despertar o interesse de mais estudantes.

\section{Considerações finais}

Diante da participação dos cinco alunos e dos relatos sobre suas expectativas, experiências e do impacto do programa de IC júnior em suas vidas é fato que esta foi uma experiência proveitosa, e impactou positivamente a vida não só dos alunos de IC júnior, mas também dos demais membros dos respectivos grupos de pesquisa.

Apesar deste artigo citar a participação e o ponto de vista de apenas cinco participantes do programa PIBIC-EM, em uma área específica (neurofisiologia), sabe-se que há o envolvimento de pessoas que estão ao seu redor, como os familiares, amigos, 
colegas e professores, pois os estudantes acabam levando os novos conhecimentos advindos de suas experiência na universidade para seu cotidiano, expandido-os e compartilhando com pessoas que fazem parte de sua vivência, portanto, é importante ressaltar que este programa também foi relevante para a divulgação da Unipampa e das possibilidades de estudo que a mesma oferece à cidade de Uruguaiana/RS, levando o conhecimento e despertando o interesse de outras pessoas sobre as variadas formas de ingresso à Universidade, tais como IC júnior, cursos de graduação e pós-graduação.

Este trabalho também poderá auxiliar em propostas futuras de atividades para outros bolsistas de IC júnior, além de indicar a importância e o impacto positivo deste programa sob a inserção de jovens estudantes na universidade.

\section{Referências}

[1] Filipecki, A.; Barros, S. S.; Elia, M. F. A visão dos pesquisadores-orientadores de um programa de vocação científica sobre a iniciação científica de estudantes de ensino médio. Ciência e educação, v. 12, n. 2., p. 199-217, 2006.

[2] Bianchetti, L.; De Oliveira, A.; Da Silva, E. L.; Turnes, L. A iniciação à pesquisa no Brasil: políticas de formação de jovens pesquisadores. Educação, Santa Maria. 37, 569-584, 2012.

[3] CNPQ. O CNPq. Disponível em <http://cnpq.br/apresentacao_institucional>. Acesso em: 09 fev. 2017.

[4] CNPQ. Objetivos do programa PIBIC. Disponível em < http://cnpq.br/pibic>. Acesso em: 09 fev. 2017.

[5] CNPQ. PIBIC-EM - Programa Institucional de Bolsas de Iniciação Científica para o Ensino Médio. Disponível em <http://www.cnpq.br/web/guest/pibic-ensino-medio>. Acesso em: 09 fev. 2017.

[6] Fava-de-moraes, F.; Fava, M. A iniciação científica: muitas vantagens e poucos riscos. São Paulo em Perspectiva, v. 14, n. 1, 2000.

[7] Santos Júnior, A. L. Universidade e sociedade: uma relação possível pelas vias de extensão universitária. Sinopse da Pesquisa de Doutorado em Educação intitulada: a extensão universitária e os entrelaços de saberes. Programa de Pós-Graduação em Educação, da Universidade Federal da Bahia, 2013.

[8] Massi, L.; Queiroz, S. L. Estudos sobre iniciação científica no Brasil: uma revisão. Cadernos de Pesquisa, v. 40, n. 139, p. 173-197, jan./abr. 2010.

[9] Conceição, A. J. Contribuições do programa de iniciação científica júnior na universidade estadual de londrina (UEL): a formação de um habitus adequado ao campo científico. Dissertação de Mestrado em 
Políticas Sociais, Universidade Estadual de Maringá, Maringá, 2012.

[10] Bazin, M. J. O Que é a iniciação científica. Revista de Ensino de Física, São Paulo, v.5, n.1, p.81-88, jun.1983.

[11] Aguiar, L. C. C. O perfil da iniciação científica no Instituto de Biofísica Carlos Chagas Filho e no Departamento de Bioquímica Médica da Universidade Federal do Rio de Janeiro. Dissertação de Mestrado em Química Biológica, Centro de Ciências da Saúde, Instituto de Ciências Biomédicas, Universidade Federal do Rio de Janeiro, Rio de Janeiro, 1997.

[12] Almeida, D. M.; Vargas, A. J. de; Rausch, R. B. Relação entre ensino e pesquisa em controladoria nos cursos de pós-graduação stricto sensu em Ciências Contábeis brasileiros 2011. Associação Nacional dos Programas de Pós-Graduação em Ciências, Vitória-ES: ANPCONT, 2011.

[13] Mendes, I. A. C. Pesquisa em enfermagem: impacto na prática. São Paulo (SP): Edusp; 1991. p.17.

[14] Pires, R. C. M. A Contribuição da iniciação científica na formação do aluno de graduação numa universidade estadual. Dissertação (Mestrado em Educação) - Faculdade de Educação, Universidade Federal da Bahia, Salvador, 2002.

[15] Breglia, V. L. A. A Formação na graduação: contribuições, impactos e repercussões do PIBIC. Tese de Doutorado em Educação, Pontifícia Universidade Católica do Rio de Janeiro, Rio de Janeiro, 2002. 